\title{
Chronic water insufficiency induced kidney damage and energy dysregulation despite reduced food intake, which improved gut microbiota in female rats
}

\author{
James W. Daily ${ }^{1} \cdot$ Ting Zhang $^{2} \cdot{\text { Xuangao } \mathrm{Wu}^{2} \cdot \text { Sunmin Park }}^{2}$ (])
}

Received: 24 November 2018 / Accepted: 17 February 2019 / Published online: 5 April 2019

(c) The Physiological Society of Japan and Springer Japan KK, part of Springer Nature 2019

\begin{abstract}
Water intake is recommended for weight loss, but the relationship between water intake and energy metabolism is not clear. We hypothesized that long-term water insufficiency would influence energy, glucose, and lipid metabolism while modulating gut microbiota. Female rats were provided with high-fat diets with different amounts of water and food intake for 6 weeks as follows: water provided for $1 \mathrm{~h}$ per day with food ad libitum (WRFA), water supply ad libitum plus pair feeding of with water restricted rats(WAFR), water restriction with ad libitum food for 3 weeks and water and food intake ad libitum for 3 weeks (WR-WA) and ad libitum supply of water and food (WAFA). Water intake in WRFA was about one-third of WAFR and WAFA, whereas food intake was lowered by $30 \%$ in WRFA and WAFR than WAFA. Body fat decreased in WRFA and WAFR, but WAFR decreased fat mass more than WRFA. Energy expenditure was lower in WRFA than WAFA and carbohydrate utilization was much higher in WRFA than the other groups. The peak serum glucose concentrations were lower in WAFA than the other groups and WRFA lowered serum insulin levels more than WAFA during OGTT. WRFA shrank the glomerulus with increased apoptotic cells and damaged renal tubules compared to the WAFA and WAFR. WR-WA also exhibited greater glomerular shrinkage and apoptosis that WAFA, but not as much WRFA, indicating that the kidneys were healing after water restriction damage. WRFA exacerbated dyslipidemia compared to the WAFA and WAFR groups. The gut microbiome was similarly modulated in WRFA and WAFR, compared to WAFA, but it was mainly affected by food intake, not water restriction in the host. WRFA and WAFR increased Bacteroidetes and decreased Firmicutes compared WAFA. In conclusion, chronic insufficient water intake induced renal damage, decreased energy expenditure, and exacerbated dyslipidemia in rats with reduced food intake. However, the reduction of food intake improved gut microbiome regardless of insufficient water intake and only minor effects on the microbiome were observed due to water restriction.
\end{abstract}

Keywords Water deprivation $\cdot$ Insulin $\cdot$ Glucose $\cdot$ Energy expenditure $\cdot$ Gut microbiota

\section{Introduction}

The human body is largely composed of water, with intracellular and extracellular water, making up 50-60\% of body weight. Water plays an important role as a medium for chemical reactions, in the excretion of waste products such as urea, and in temperature regulation. Water contents are

Sunmin Park

smpark@hoseo.edu

$1 \quad$ R\&D, Daily Manufacturing, Rockwell, NC, USA

2 Department of Food and Nutrition, Obesity/Diabetes Center, Hoseo University, 165 Sechul-Ri, BaeBang-Yup, Asan-Si, ChungNam-Do, Asan 336-795, South Korea different in various tissues according to the content of fat. Since women have more fat in the body, they have a higher water turnover regardless of physical activity. Therefore, women may be more susceptible to water loss than men [1]. Adults can survive only a few days without drinking water since water removes body wastes via urine, resulting in the loss of about 1-2 1 of water every day, depending on the fluid intake [2]. Insufficient water intake is indicated by a urine osmolality of over $800 \mathrm{mOsm} / \mathrm{kg}$. Young women require total fluid intakes (sum of water, beverage, and moisture in food) $\geq 2.41 /$ day and urine volume $>1.31 /$ day [3]. Less than $600 \mathrm{ml} /$ day of urine volume indicates that the kidney concentrated the urine due to water deficiency. However, some people do not drink enough water. 
Body water distribution is maintained by osmosis with minerals, mainly sodium and potassium ions. Water contents in the body are balanced by its intake and excretion, which are regulated by thirst and anti-diuretic hormone (vasopressin), respectively. A decrease in blood volume or low blood pressure due to water insufficiency or high mineral concentrations releases vasopressin from the hypothalamus $[2,4]$. The hormone increases water retention by water reabsorption in the renal tubule to control blood pressure by acting on the kidneys and the blood vessels [4]. As a result, the fluid volume of the body is conserved. Low intake of water increases the likelihood that heavy metals will be deposited in the glomerulus of the kidney and the risk of kidney damage increases [5]. The development of kidney diseases by dehydration is also associated with cell cycle arrest, double-strand DNA breaks, disruption of repair mechanisms, oxidative stress, and inhibition of transcription and translation [6]. Since water is consistently lost via the insensible route including feces, skin, and lung, dehydration decreases the insensible and sensible water loss, the gut may have less water content to alter the environments of gut microbiomes. Thus, insufficient water intake may increase the risk of kidney diseases such as kidney stone and change gut microbiome.

Vasopressin has various functions besides decreasing urine volume [4]. It also increases the blood flow by increasing the contraction of blood vessels and signaling the nervous systems to supply oxygen and nutrients and remove waste products with a smaller volume of blood [7]. Vasopressin is involved in platelet aggregation, blood pressure regulation, and temperature regulation [4]. Increasing scientific evidence suggests that anti-diuretic hormone influences glucose and lipid metabolism. The activation of vasopressin- $1 \alpha$ receptor elevates fasting serum glucose levels and impairs glucose tolerance in obese rats [4]. This is associated with the activation of the hypothalamus-pituitary-adrenal (HPA) axis by vasopressin: the hormone stimulates adrenocorticotrophic hormone, resulting in the release of cortisol through pituitary vasopressin-1B receptors [8]. The hormone also exerts negative effects on gut perfusion, the motor of the systemic inflammatory response syndrome [9]. The changes in the gut microbiome community alter the energy, glucose, and lipid metabolism in addition to inflammation $[10,11]$. Thus, water deficiency may modulate central and systemic metabolism through several pathways including the gut microbiome community. However, few studies examine the effect of water deficiency on the gut microbial community and systemic metabolism.

Chronic insufficient water intake may influence not only kidney function but also energy, glucose, and lipid metabolism while modulating the gut microbiome. However, few studies have been conducted to examine chronic restriction of water intake $[12,13]$ although acute water deprivation is known to have an impact on metabolism [14]. We hypothesized that long-term water insufficiency would influence energy, glucose, and lipid metabolism, and modulate gut microbiota in diet-induced animals. The hypothesis was examined in male diet-induced obese Sprague-Dawley rats fed high-fat diets with limited water intake for 6 weeks. Water intake is recommended for weight loss to reduce hunger from less intake of food $[15,16]$. In NHANES 2009-2012, there is a significant association between inadequate hydration and elevated BMI in a cross-sectional study [15]. Since body fat is associated with water intake [17], a high-fat diet induces excessive body fat with body water loss. Female rats fed a high diet were used as an experimental animal model in the present study.

\section{Materials and methods}

\section{Animals and ethics}

Nine-week-old female Sprague-Dawley rats (weight, $261 \pm 15 \mathrm{~g}$ ) were housed individually in stainless-steel cages in a controlled environment $\left(23^{\circ} \mathrm{C} ; 12\right.$-h light/dark cycle). All experimental procedures were conducted according to the Guide for the Care, and Use of Laboratory Animals from the National Institutes of Health (NIH) and were approved by the Institutional Animal Care and Use Committee of Hoseo University (HUACUC-17-47).

\section{Experimental design}

Forty rats were randomly assigned to the four groups and the 6-week treatment protocol was assigned to each group. The rats in the water-sufficient group had free access to water, whereas those in the water-restricted group had water for $1 \mathrm{~h}$ (9 AM-10 AM) since water was daily provided for $1-2 \mathrm{~h}$ in chronic water-restriction studies [13]. Water intake of all rats was recorded daily. The experimental groups were as follows: (1) water restriction with ad libitum intake of food (WRFA; $n=10)$, (2) free water intake plus pair feeding of food as much as consumed by water-restricted rats (WAFR; $n=10$ ), (3) water restriction with ad libitum intake of food for 3 weeks and switching to ad libitum intake of water and food for 3 weeks (WR-WA; $n=10$ ), and (4) ad libitum intake of water and food (WAFA; $n=10$ ). Total intervention periods of each assigned treatment were 6 weeks. All rats were fed the same diets made with a modified semi-purified AIN-93 formulation for experimental animals [18] that consisted of 42 energy $\%$ carbohydrate, 15 energy $\%$ protein, and 43 energy $\%$ fat. The major carbohydrate, protein, and fat sources were starch and sugar, casein (milk protein), and lard (CJ Co., Seoul, Korea), respectively. Since dehydration is associated with energy metabolism and increases the 
incidence of obesity [15], diets containing 43 energy $\%$ fat were provided in all rats to exacerbate the metabolic disruption during water deprivation in the present study.

\section{Body composition}

Body composition was examined before and after providing water and food for 6 weeks. After anesthetizing the rats with ketamine and xylazine, they were laid with their hind legs maintained in external rotation and hip, knee and ankle articulations in $90^{\circ}$ flexion with tape. The body was scanned by dual-energy X-ray absorptiometry (DEXA) method using an absorptiometer (pDEXA Sabre; Norland Medical Systems Inc., Fort Atkinson, WI, USA). The facility was equipped with the appropriate software for assessment in small animals. Bone mineral density was determined in the lumbar spine and femur and lean body mass was determined in the hip and leg, as previously described [19]. Fat mass was also measured in the abdomen and leg.

\section{Energy expenditure by indirect calorimetry}

After 39 days of the assigned treatment, energy expenditure was assessed at the beginning of the dark phase of the light-dark cycle after $6 \mathrm{~h}$ of feed deprivation. The rats were placed into metabolic chambers (airflow $800 \mathrm{ml} / \mathrm{min}$ ) equipped with a computer-controlled $\mathrm{O}_{2}$ and $\mathrm{CO}_{2}$ measurement system (Biopac Systems Inc., Goleta, CA, USA). The respiratory quotient (RQ) and resting energy expenditure (REE) were calculated using the equations provided by Niwa et al. [20]. Average oxygen consumption $\left(V \mathrm{O}_{2}\right)$ and average carbon dioxide production $\left(\mathrm{VCO}_{2}\right)$ were calculated using previously published methods and used to calculate carbohydrate and fat oxidation and the amount of oxygen consumed per gram of substrate oxidized [21, 22].

\section{Metabolic analysis}

Overnight-fasted serum glucose levels, food intake, and body weights were measured every week. An oral glucose tolerance test (OGTT) was performed at 5 weeks after starting the water and food protocol in overnight-fasted animals by orally administering $2 \mathrm{~g}$ glucose $/ \mathrm{kg}$ body weight [23]. At 4 days after OGTT, an intraperitoneal insulin tolerance test (IPITT) was conducted after the food was removed for $6 \mathrm{~h}$. The serum glucose levels were measured every 15 min for 90 min after an intraperitoneal injection of insulin $(0.75 \mathrm{U} /$ $\mathrm{kg}$ body weight). Serum glucose and insulin levels were analyzed with a Glucose Analyzer II (Beckman-Coulter, Palo Alto, CA, USA) and Ultrasensitive rat insulin kit (Crystal Chem; Elk Grove Village, IL, USA), respectively.

At 3 days after conducting the IPITT, the rats fasted for $16 \mathrm{~h}$ and they were anesthetized with ketamine and xylazine
(100 and $10 \mathrm{mg} / \mathrm{kg}$ body weight, respectively). Before sacrificing the rats, blood $(1 \mathrm{ml})$ was collected by cardiac puncture, and the serum was separated by centrifugation at $3000 \mathrm{rpm}$ for $20 \mathrm{~min}$. Tissues were then collected and stored at $-70{ }^{\circ} \mathrm{C}$ for biochemical analysis. The epididymal and retroperitoneal fat masses were weighed. Serum glucose and insulin levels were measured using a colorimetry kit (Asan Pharm., Seoul, Korea) and Ultra-sensitive insulin ELISA kit (Crystal Chem, Elk Grove Village, IL, USA), respectively. The homeostasis model assessment for insulin resistance index (HOMA-IR) was calculated as follows: serum insulin $(\mu \mathrm{U}) \times$ serum glucose $(\mathrm{mmol} / \mathrm{l}) / 22.5$ [24]. Lipid profiles including total cholesterol, HDL cholesterol, and triglyceride levels in the serum were measured by colorimetry kits (Asan Pharm., Seoul, Korea) [25]. Serum LDL cholesterol levels were calculated using the Friedwald equation [25]. Serum aspartate aminotransferase (AST), alanine aminotransferase (ALT), blood urinary nitrogen (BUN), and creatinine levels were also measured by colorimetry kits (Asan Pharm., Seoul, Korea). Serum aldosterone and arginine vasopressin levels were measured using ELISA kits from Enzo Life Science (Farmingdale, NY, USA). Serum osmolarity was measured by osmometry (Advanced Micro-Osmometer Model, Advanced Instruments, Inc).

The liver was lysed with lysis buffer ( $20 \mathrm{mM}$ Tris buffer, $\mathrm{pH} 7.4$ ) containing $137 \mathrm{mM} \mathrm{NaCl}, 10 \%$ glycerol, $1 \% \mathrm{NP} 40$, $2 \mathrm{mM}$ EGTA, $12 \mathrm{mM} \alpha$-glycerol phosphate, and protease inhibitors. Liver lysates were centrifuged at $3000 \mathrm{rpm}$ for $10 \mathrm{~min}$ and the supernatants deproteinized with $1.5 \mathrm{~N}$ perchloric acid. The glycogen content was calculated from glucose concentrations derived from glycogen hydrolyzed by $\alpha$-amyloglucosidase in an acid buffer. Triacylglycerol was extracted from the livers with chloroform-methanol (2:1, $\mathrm{vol} / \mathrm{vol}$ ) and resuspended in pure chloroform [25]. After evaporating the chloroform, the residues were suspended with PBS with $0.1 \%$ Triton X-100, and the suspension was sonicated and boiled for $5 \mathrm{~min}$. The triacylglycerol contents of the suspensions were assayed using a Trinder kit (Asan).

Renal medulla tissues were homogenized with lysis buffer, and the supernatants were collected by centrifugation of the lysates at $3000 \times g$ for $15 \mathrm{~min}$. Malondialdehyde (MDA) levels in the lysates were measured by proportionally binding with thiobarbituric acid, and the color change was determined at $532 \mathrm{~nm}$ using a spectrophotometer [26, 27]. TNF- $\alpha$ levels in the lysates were measured with ELISA kits from eBioscience (San Diego, CA, USA).

\section{Real-time quantitative reverse transcriptase polymerase chain reaction (RT-PCR)}

Total RNA of renal medulla tissues was isolated using a monophasic solution of phenol and guanidine isothiocyanate (TRIzol reagent, Invitrogen, Rockville, MD, USA). The 
cDNA was synthesized from total RNA with superscript III reverse transcriptase and high fidelity Taq DNA polymerase $(1: 1: 1, \mathrm{v}: \mathrm{v}: \mathrm{v})$ by reverse transcription reaction in polymerase chain reaction (PCR). The synthesized cDNA was mixed with the primers of the interest genes and SYBR Green mix, and their expressions were analyzed using a real-time PCR machine (Bio-Rad Laboratories, Hercules, CA, USA). The primers were used as follows: tumor necrosis factor (TNF)- $\alpha$ (forward 5'-CCCTGGTACTAACTCCCAGAAA-3', reverse 5'-TGTATGAGAGGGACGGAACC-3'), interleukin (IL)-1 $\beta$ (forward 5'-CACCTCTCAAGCAGAGCACAG-3', reverse 5'-GGGTTCCATGGTGAAGTCAAC-3'), Cu/Zn superoxide dismutase (SOD; forward 5'-CACTCTAAGAAACAT GGCG-3', reverse 5'-CTGAGAGTGAGATCACACG-3'), glutathione peroxidase (GSH-Px; forward 5'-GCGGGC CCTGGCATTG-3', reverse 5'-GGACCAGCGCCCATCTG$3^{\prime}$ ) and $\beta$-actin (forward 5'-AGCGTGGCTACAGCTTCA CC-3', reverse 5'-AAGTCTAGGGCAACATAGCACAGC $\left.-3^{\prime}\right)$. Their relative gene expression was quantitated using the comparative cycle of threshold (CT) method $\left(2^{-\Delta \Delta C_{\mathrm{T}}}\right.$ method) as previously described by Livak and Schmittgen [28].

\section{Immunohistochemistry}

At the end of experimental period, the overnight-fasted rats were anesthetized with a mixture of ketamine and xylazine, and the kidney was dissected immediately, perfused with saline and a $4 \%$ paraformaldehyde solution $(\mathrm{pH} 7.2)$ sequentially, and post-fixed with the same fixative overnight at room temperature [29].

Two serial 5- $\mu \mathrm{m}$ paraffin-embedded kidney sections were selected from the seventh or eighth sections to avoid the same area of the kidney twice [29]. The kidney sections were stained with hematoxylin-eosin. Each kidney section was assessed by examining all non-overlapping images in two H\&E sections from each rat at $200 \times$ magnification with a Zeiss Axiovert microscope (Carl Zeiss Microimaging, Thornwood, NY, USA). Apoptosis of glomerular cells was detected by in situ apoptosis detection with a TUNEL Assay Kit (Roche Diagnostics, Mannheim, Germany) and it was calculated by the total number of apoptotic nuclei per glomerular area in the kidney section. Hematoxylin was counter-stained for the nucleus.

\section{Next-generation sequencing (NGS) gut microbiome}

Gut microbiome was analyzed from the feces in the cecum by metagenome sequencing using NGS as previously described [19, 30]. In brief, the fecal bacteria were collected from the dissected cecum of each rat into the sterile saline in a sterile hood. Bacterial DNA was extracted using a Power Water DNA Isolation Kit (MoBio, Carlsbad, CA,
USA). According to the GS FLX plus library prep guide, each library was prepared using polymerase chain reaction (PCR) products. The libraries were quantified using Picogreen assay (Victor 3). Corresponding to clonal amplification of the purified library, the emPCR was conducted using the GS-FLX plus emPCR Kit (454 Life Sciences, Branford, CT, USA). The beads containing DNA were purified using the biotinylated primer A (complementary to adaptor A), that bound to streptavidin-coated magnetic beads. The DNA library beads were isolated by melting the double-stranded amplification products and the sequencing primer was annealed to the amplified singlestranded DNA with a Particle Counter (Beckman Coulter). Sequencing of fecal bacterial DNA was carried out by a Genome Sequencer FLX plus (454 Life Sciences) at Macrogen Ltd. (Seoul, Korea). Each sample was loaded in one region of a 70-75-mm PicoTiter plate (454 Life Sciences) fitted with an eight-lane gasket. The bacterial identification and analysis were performed by Mothur program.

\section{Statistical analyses}

All data are expressed as means \pm standard deviations, and all statistical analyses were performed using SAS ver. 9.1 (SAS Institute, Cary, NC, USA). Significant differences among the groups were identified by one-way analyses of variance. Significant differences in the main effects among the groups were detected for post hoc analysis using Tukey's tests. A $p$ value $<0.05$ was considered significant.

\section{Results}

\section{Water metabolism}

Water intake in WRFA was one-third of the WAFA and WAFR had a higher water intake than WAFA. WR-FA had a similar intake of WAFA $(p<0.05$; Table 1$)$. Serum aldosterone and vasopressin levels were higher in WRFA than the other groups $(p<0.05$; Table 1$)$. The increase of these hormones in WRFA was related to increased water reabsorption in the kidney. However, kidney weight was not significantly different among the groups (Table 1). Serum creatinine and BUN concentrations were higher in WAFR than the other group and the concentrations tended to be lower in WAFR than WAFA but it was not significantly different (Table 1). However, serum osmolarity levels increased in ascending order of WAFR, WR-WA, WAFA, and WRFA (Table 1). These results indicated that water restriction increased osmolality with increasing nitrogen-containing wastes. 
Table 1 Water intake and biochemical parameters related water metabolism

\begin{tabular}{|c|c|c|c|c|}
\hline & WAFA & WRFA & WAFR & WR-WA \\
\hline Water intake (ml/day) & $30.8 \pm 2.2^{\mathrm{b}}$ & $11.9 \pm 1.0^{\mathrm{c}}$ & $38.7 \pm 2.3^{\mathrm{a}}$ & $11.3 \pm 0.9^{\mathrm{c}} / 31.5 \pm 2.5^{\mathrm{b}}$ \\
\hline Serum aldosterone $(\mathrm{pg} / \mathrm{ml})$ & $205 \pm 28^{\mathrm{b}}$ & $255 \pm 29^{a}$ & $201 \pm 23^{b}$ & $197 \pm 25^{b}$ \\
\hline Serum vasopressin $(\mathrm{ng} / \mathrm{ml})$ & $1.04 \pm 0.12^{\mathrm{b}}$ & $1.43 \pm 0.17^{\mathrm{a}}$ & $0.98 \pm 0.13^{\mathrm{b}}$ & $1.03 \pm 0.14^{\mathrm{b}}$ \\
\hline Serum creatinine $(\mathrm{mg} / \mathrm{dl})$ & $1.91 \pm 0.18^{\mathrm{b}}$ & $2.82 \pm 0.34^{\mathrm{a}}$ & $1.84 \pm 0.25^{\mathrm{b}}$ & $2.04 \pm 0.27^{\mathrm{b}}$ \\
\hline Serum BUN (mg/dl) & $18.5 \pm 2.4^{\mathrm{b}}$ & $26.7 \pm 3.1^{\mathrm{a}}$ & $17.6 \pm 2.0^{\mathrm{b}}$ & $19.7 \pm 2.7^{\mathrm{b}}$ \\
\hline Serum osmolarity $\left(\mathrm{mOsm} / \mathrm{kg} \mathrm{H}_{2} \mathrm{O}\right)$ & $295 \pm 2.59^{\mathrm{b}}$ & $315 \pm 2.28^{\mathrm{a}}$ & $290 \pm 2.25^{\mathrm{c}}$ & $299 \pm 2.94^{\mathrm{b}}$ \\
\hline Kidney weight $(\mathrm{g})$ & $1.98 \pm 0.12$ & $1.98 \pm 0.07$ & $1.93 \pm 0.09$ & $1.98 \pm 0.07$ \\
\hline Kidney malondialdehyde levels (nmol/mg protein) & $3.8 \pm 0.6^{\mathrm{b}}$ & $5.6 \pm 0.9^{\mathrm{a}}$ & $2.4 \pm 0.4^{\mathrm{c}}$ & $4.0 \pm 0.7^{\mathrm{b}}$ \\
\hline Kidney $\mathrm{Cu} / \mathrm{Zn}$ SOD expression (fold increase of the control) & $1.0 \pm 0.07^{\mathrm{b}}$ & $1.53 \pm 0.18^{\mathrm{a}}$ & $0.98 \pm 0.15^{\mathrm{b}}$ & $1.07 \pm 0.15^{\mathrm{b}}$ \\
\hline Kidney GSH-Px expression (fold increase of the control) & $1.0 \pm 0.06^{\mathrm{b}}$ & $1.47 \pm 0.16^{\mathrm{a}}$ & $1.01 \pm 0.17^{\mathrm{b}}$ & $1.06 \pm 0.16^{\mathrm{b}}$ \\
\hline Kidney TNF- $\alpha$ levels (pg/mg protein) & $8.3 \pm 1.1^{\mathrm{b}}$ & $15.4 \pm 2.6^{\mathrm{a}}$ & $5.2 \pm 0.9^{c}$ & $8.9 \pm 1.3^{\mathrm{b}}$ \\
\hline Kidney TNF- $\alpha$ expression (fold increase of the control) & $1.0 \pm 0.07^{\mathrm{b}}$ & $2.14 \pm 0.39^{\mathrm{a}}$ & $0.77 \pm 0.10^{\mathrm{c}}$ & $1.03 \pm 0.12^{\mathrm{b}}$ \\
\hline Kidney IL-1 $\beta$ expression (fold increase of the control) & $1.0 \pm 0.06^{\mathrm{b}}$ & $1.87 \pm 0.28^{\mathrm{a}}$ & $0.71 \pm 0.09^{c}$ & $1.05 \pm 0.13^{\mathrm{b}}$ \\
\hline
\end{tabular}

Female rats had the following regime for 6-week ad libitum supply of water and food (normal-control), water supply for $1 \mathrm{~h}$ per day with ad libitum food intake (WRFA), and ad libitum water supply plus pair feeding of food as much as WRFA (WAFR). Rats in WR-WA had water restriction for 3 weeks and ad libitum water supply with ad libitum food intake for 3 weeks. Values represent mean $\pm \operatorname{SD}(n=10)$

a, b, c Different letters besides mean \pm SD indicate significant differences among the groups at $p<0.05$

\section{Kidney damage and morphology}

The levels of MDA, an index of lipid peroxidation, were much higher in WRFA than WAFA, whereas they were lower in the WAFR than WAFA $(p<0.05$; Table 1$)$. WR-WA showed similar levels of MDA as WAFA (Table 1). The increase in MDA was associated with $\mathrm{Cu} / \mathrm{Zn}$ SOD and GSHPx expression and the production of lipid peroxides. The expression of $\mathrm{Cu} / \mathrm{Zn}$ SOD and GSH-Px was higher in WRFA than WAFA but it was not different among the WAFA, WAFR and WR-WA groups $(p<0.05$; Table 1$)$. Thus, the increased expressions of SOD and GSH-Px could not compensate for the production of MDA in WRFA although their expressions were increased.

The TNF- $\alpha$ levels, a proinflammatory cytokine, in the kidney was higher in WRFA than WAFA and was lower in WAFR than WAFA $(p<0.05$; Table 1$)$. The expression of TNF- $\alpha$ and IL- $1 \beta$ also showed a similar pattern to that of TNF- $\alpha$ levels in the kidney. The expression of TNF- $\alpha$ and IL- $1 \beta$ were lower in the descending order of WRFA, WAFA, WR-WA, and WAFR $(p<0.05$; Table 1$)$. Thus, water restriction increased the inflammatory status, even though the rats in WRFA consumed less food.

The kidney sections showed that glomeruli were shrunk and renal tubules were enlarged in WRFA compared to WAFA (Fig. 1a). WR-WA had partly shrunk glomeruli, but the shapes of renal tubules were unchanged in comparison to the WAFA (Fig. 1b). The glomeruli and renal tubules in WAFR did not differ from those in WAFA (Fig. 1b). Thus, water restriction, but not food restriction, had a harmful effect on the glomerulus and renal tubules. Short-term water restriction damaged the glomerulus but restoring water intake resulted in partial recovery.

Apoptosis in the glomerular nuclei detected by TUNEL assay was elevated in the WRFA compared to WAFA and WAFR (Fig. 1b, c). Interestingly, WR-WA had more apoptosis of glomerular cells than WAFA (Fig. 1c, d), indicating that the recovery of apoptosis in the glomerular cells from water restriction might take more time than the recovery of glomerular shrinkage.

\section{Energy metabolism}

Body weight at 3 weeks was higher in the WAFA group than the other groups whereas body weight was still higher in WAFA than WRFA and WAFR at 6 weeks $(p<0.05)$. However, WR-WA were not different from any of the other groups (Table 2). As a result, body weight gain was much lower with WRFA and WAFR than WAFA $(p<0.05$; Table 2$)$. The rats in the WAFR group (pair-fed with the WRFA rats) had less food intake than the WAFA group (Table 2). Water intake in the WRFA group was about one-third of that in the WAFA group, and interestingly, WAFR had higher water intake than WAFA $(p<0.05$; Table 2$)$. Thus, less weight gain in the WRFA and WAFR was associated with less food intake not due to less water intake.

In addition to food intake, energy expenditure is associated with body weight. Daily energy expenditure was lower in WRFA than WAFA $(p<0.05)$, but energy expenditure was not significantly lower in the WAFR group than in the WAFA (Table 2). This suggested that water intake might be involved in energy expenditure. RQ was higher in the 
Fig. 1 Kidney morphology. Female rats were assigned to the following regime for 6 weeks. Ad libitum supply of water and food (normalcontrol, WAFA), water supply for $1 \mathrm{~h}$ per day with ad libitum food intake (WRFA), and ad libitum water supply plus pair feeding of food to as much as WRFA (WAFR). Rats in WR-WA had water restriction for 3 weeks and ad libitum water supply with ad libitum food intake for 3 weeks. At the end of the experiment, kidneys were embedded into paraffin and its section was stained with hematoxylin and eosin (a). The kidney damage was scored by the shrinkage of glomerulus and shape of renal tubules from the H\&E-stained sections and the percentage of apoptotic cells in the glomerulus by TUNEL assay (b). Higher scores indicated greater renal damage. Apoptotic cells (brown dots) in the glomerulus were stained by immunohistochemistry by an in situ Cell Death TUNEL kit (c). The brown dots represent the apoptotic cells. Each bar and error bar represents mean $\pm \operatorname{SD}(n=10)$. ${ }^{\mathrm{a}, \mathrm{b}}$, ${ }^{\mathrm{c}}$ Bars with a different letters differ significantly at $p<0.05$

WRFA group than other groups (Table 2). Rats in the WAFA group had higher oxygen consumption than those in the WRFA and WAFR groups ( $p<0.05$; Table 2$)$. CHO oxidation was increased in the ascending order of WAFR, WRFA WR-WA, and WAFA groups ( $p<0.05$; Table 2$)$. In contrast to $\mathrm{CHO}$ oxidation, fat oxidation decreased in the descending order of WAFA, WAFR, WR-WA, and WRFA (Table 2). Thus, restricted water intake decreased energy expenditure, increased carbohydrate oxidation, and decreased fat oxidation, but less food intake with sufficient water intake did not decrease energy expenditure.

Consistent with body weight, visceral fat mass, the sum of retroperitoneal and uterine fat mass, was much higher in WAFA than WRFA and WAFR groups ( $p<0.05$; Table 2$)$. Visceral fat mass of the WR-WA group was shown in between WAFA and WRFA (Table 2). Thus, fat mass was related to food intake, not water restriction.

\section{Body composition}

Bone mineral density in the lumbar spine and femur was much lower in the WRFA and WAFR than WAFA $(p<0.05$; Fig. 2a). Bone mineral density was partly restored in WR-WA, compared to WRFA (Fig. 2a). LBM in the hip was higher in WAFR than WAFA. However, LBM in the leg did not differ among the groups (Fig. 2b). Fat mass was lower in the descending order of WAFA, WR-WA, WRFA, and WAFR in the abdomen and leg $(p<0.05$; Fig. 2c). Thus, food deficit decreased bone mineral density and lean body mass regardless of water restriction. Lean body mass increases with food restriction might be associated with reducing fat mass, but water restriction did not increase lean body mass as much as WAFR.

\section{Glucose metabolism}

Serum glucose concentrations at overnight-fasted states were lower in WRFA than the WAFA and WR-WA

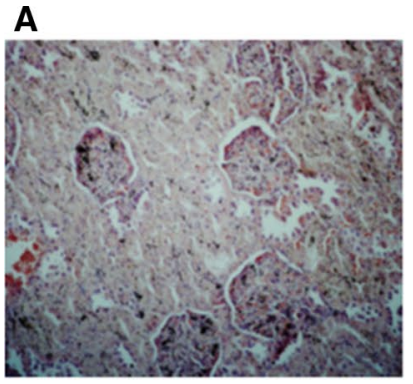

WAFA

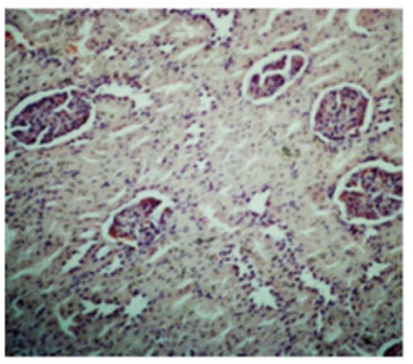

WAFR

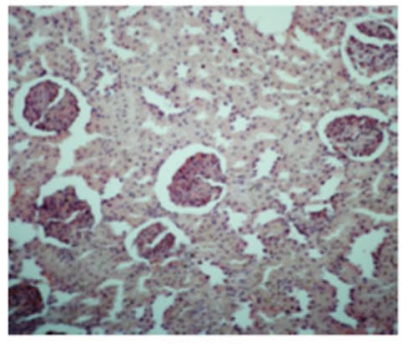

WRFA

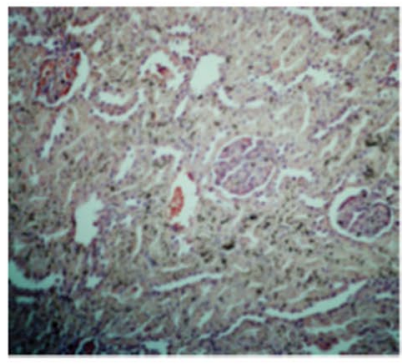

WR-WA

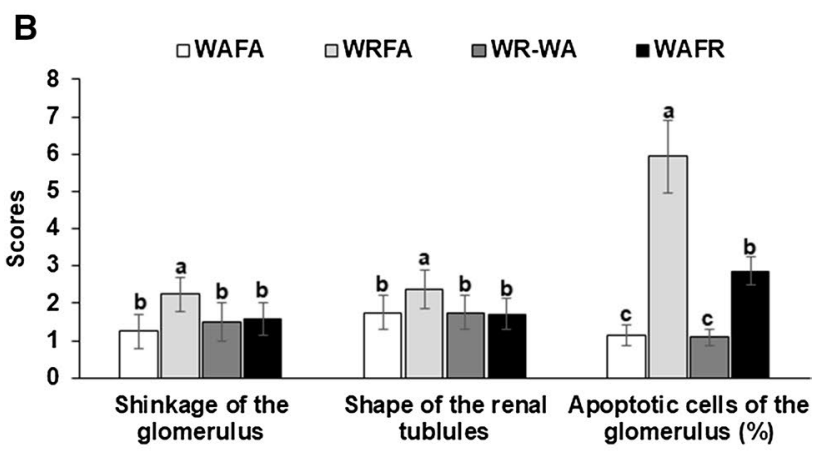

C
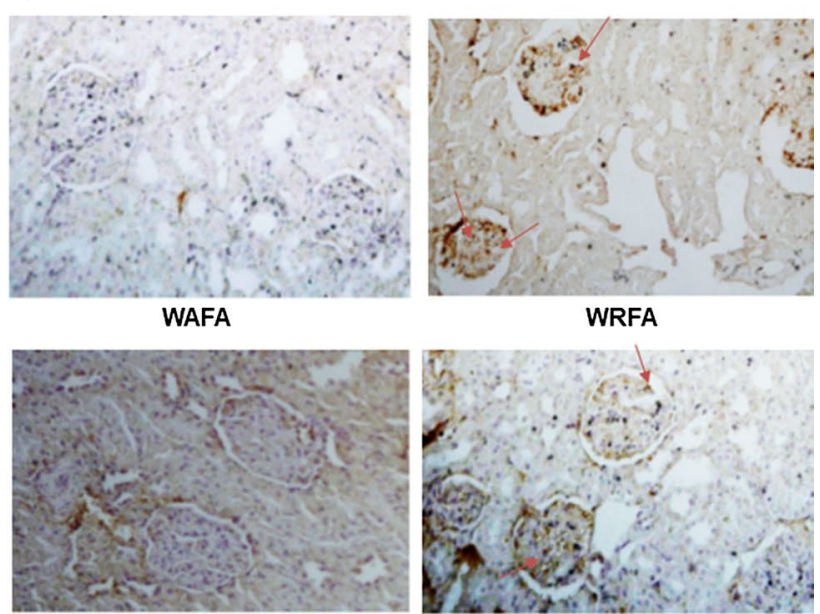

WAFR

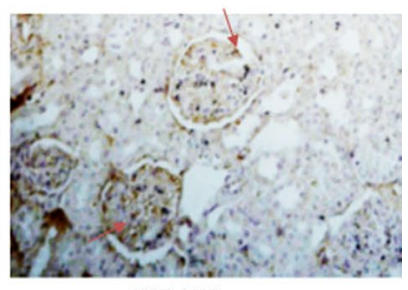

WR-WA

$(p<0.05$; Table 3). Serum insulin concentrations were not significantly different among the groups (Table 3 ). HOMA-IR, an index of insulin resistance, was also not significantly different (Table 3 ). Although fasting serum glucose concentrations were lower in the WRFA, peak 
Table 2 Energy metabolism and body fat mass

\begin{tabular}{|c|c|c|c|c|}
\hline & WAFA & WRFA & WAFR & WR-WA \\
\hline Body weight at third week (g) & $307 \pm 15^{\mathrm{a}}$ & $280 \pm 12^{b}$ & $276 \pm 15^{\mathrm{b}}$ & $283 \pm 16^{\mathrm{b}}$ \\
\hline Final body weight (g) & $330 \pm 17^{\mathrm{a}}$ & $297 \pm 18^{b}$ & $292 \pm 13^{b}$ & $318 \pm 19^{\mathrm{ab}}$ \\
\hline Body weight gain during 7 weeks (g) & $68.8 \pm 4.7^{\mathrm{a}}$ & $34.9 \pm 4.6^{\mathrm{c}}$ & $30.4 \pm 4.2^{\mathrm{c}}$ & $56.3 \pm 5.8^{\mathrm{b}}$ \\
\hline Food intake (g/day) & $14.5 \pm 1.6^{\mathrm{a}}$ & $10.3 \pm 1.2^{\mathrm{b}}$ & $9.8 \pm 1.0^{\mathrm{b}}$ & $\begin{array}{l}9.7 \pm 1.0^{\mathrm{b}} / \\
14.7 \pm 1.5^{\mathrm{a}}\end{array}$ \\
\hline Energy expenditure $\left(\mathrm{kcal} \mathrm{kg}^{-0.75}\right.$ days $\left.^{-1}\right)$ & $129 \pm 12^{\mathrm{a}}$ & $115 \pm 10^{\mathrm{b}}$ & $121 \pm 12^{\mathrm{ab}}$ & $124 \pm 11^{\mathrm{a}}$ \\
\hline Respiratory quotient & $0.82 \pm 0.07^{b}$ & $0.95 \pm 0.07^{\mathrm{a}}$ & $0.84 \pm 0.08^{b}$ & $0.86 \pm 0.07^{b}$ \\
\hline$\left(V \mathrm{O}_{2}, \mathrm{ml} \mathrm{kg}^{-0.75} \mathrm{~min}^{-1}\right)$ & $18.4 \pm 1.6^{\mathrm{a}}$ & $16.4 \pm 1.5^{\mathrm{b}}$ & $16.8 \pm 1.5^{\mathrm{b}}$ & $17.7 \pm 1.6^{\mathrm{ab}}$ \\
\hline $\begin{array}{l}\text { Carbohydrate oxidation } \\
\left(\mathrm{mg} \mathrm{kg}^{-0.75} \mathrm{~min}^{-1}\right)\end{array}$ & $5.4 \pm 0.5^{\mathrm{c}}$ & $9.9 \pm 0.8^{\mathrm{a}}$ & $5.8 \pm 0.6^{\mathrm{c}}$ & $7.1 \pm 0.7^{b}$ \\
\hline $\begin{array}{l}\text { Fat oxidation } \\
\left(\mathrm{mg} \mathrm{kg}^{-0.75} \min ^{-1}\right)\end{array}$ & $8.3 \pm 0.8^{\mathrm{a}}$ & $2.2 \pm 0.4^{\mathrm{c}}$ & $6.8 \pm 0.7^{b}$ & $6.1 \pm 0.6^{\mathrm{b}}$ \\
\hline Uterine fat mass $(\mathrm{g})$ & $10.1 \pm 2.3^{\mathrm{a}}$ & $4.8 \pm 0.9^{\mathrm{c}}$ & $3.6 \pm 0.5^{\mathrm{d}}$ & $7.6 \pm 1.2^{\mathrm{b}}$ \\
\hline Retroperitoneal fat mass (g) & $6.8 \pm 0.5^{\mathrm{a}}$ & $3.2 \pm 0.5^{\mathrm{c}}$ & $2.6 \pm 0.5^{\mathrm{d}}$ & $5.1 \pm 0.7^{\mathrm{b}}$ \\
\hline Visceral fat mass (g) & $16.9 \pm 1.9^{\mathrm{a}}$ & $8.0 \pm 1.4^{\mathrm{c}}$ & $6.2 \pm 0.9^{\mathrm{d}}$ & $12.7 \pm 1.9^{\mathrm{b}}$ \\
\hline
\end{tabular}

Female rats had the following regime for 6-week ad libitum supply of water and food (normal-control), water supply for $1 \mathrm{~h}$ per day with ad libitum food intake (WRFA), and ad libitum water supply plus pair feeding of food as much as WRFA (WAFR). Rats in WR-WA had water restriction for 3 weeks and ad libitum water supply with ad libitum food intake for 3 weeks. Values represent mean $\pm \operatorname{SD}(n=10)$

${ }^{\mathrm{a}, \mathrm{b}, \mathrm{c}}$ Different letters besides mean $\pm \mathrm{SD}$ indicate significant differences among the groups at $p<0.05$ serum glucose concentrations (20-30 min) were higher than WAFA and WAFR after the challenge of $2 \mathrm{~g}$ glucose/ kg bw $(p<0.05$; Fig. 3a). Serum glucose concentrations quickly decreased after $30 \mathrm{~min}$ in all groups $(p<0.05$; Fig. 3a). AUC of serum glucose concentrations at the 1st part (0-40 min) was lower in the WAFA and WR-FA than the WRFA and WAFR, whereas that at the 2nd part $(40-120 \mathrm{~min})$ were higher in WRFA than WAFR $(p<0.05$; Fig. 3b). The differences in serum glucose concentrations during OGTT might be associated with serum insulin concentrations. Serum insulin during OGTT increased at 20 min after a glucose load, and the peak of serum insulin concentrations was lowest in WRFA among all groups $(p<0.05$; Fig. 3c). The serum insulin decreased from the peak in all groups and was lower in the descending order of WAFA, WR-WA, WAFR, and WRFA $(p<0.05$; Fig. 3c). The results indicated that serum insulin was lowest WRFA and was also lower in WAFR than WAFA and WR-WA during the OGTT.

Serum glucose concentrations quickly decreased until $45 \mathrm{~min}$ and then they were maintained in all rats after an intraperitoneal injection of insulin (Fig. 4a). The concentrations were overall lower in WRFA and WAFR than the WAFA and WR-WA. AUC of the 1st part (0-45 min) during IPITT was lower in the WRFA and WAFR than the WAFA and WR-WA $(p<0.05$; Fig. $4 \mathrm{~b})$. The AUC of the 2nd part (45-90 min) decreased in the order of WR-WA, WAFA, WRFA, and WAFR ( $p<0.05$; Fig. 4b). These results indicated that WAFR and WRFA reduced insulin resistance.

\section{Lipid metabolism and liver damage}

Serum total cholesterol concentrations were higher in WRFA than WAFA $(p<0.05)$ whereas serum HDL cholesterol and triglyceride concentrations were not significantly different among the groups (Table 3). Serum LDL cholesterol concentrations calculated by the Friedwald equation were higher in WRFA than the other groups (Table 3). The results suggested that WRFA exacerbated dyslipidemia compared to the WAFA and WAFR groups and WAFR was not different from the WAFA group.

Serum levels of AST and ALT increased in WRFA, and they decreased in WAFR compared to the WAFA and WRFA $(p<0.05$; Table 3$)$. WRFA caused some liver damage compared to WAFA. In addition, hepatic triglyceride contents were higher in WRFA than the other groups, whereas hepatic glycogen contents were higher in the ascending order of WAFA, WR-WA, WRFA, and WAFR ( $p<0.05$; Table 3$)$.

\section{Gut microbiome}

Principal coordinate analysis (PCoA) revealed a separation of the gut bacterial community in separate groups (Fig. 5a). WAFA and WR-WA shared similar clustering of gut microbiota whereas WRFA and WAFR had similar clustering. WAFA had a clearly separated clustering from WRFA and WAFR. Thus, lower food intake influenced gut microbiome rather than water restriction.

In the analysis of molecular variance (AMOVA), the gut microbiota community was significantly different among the 

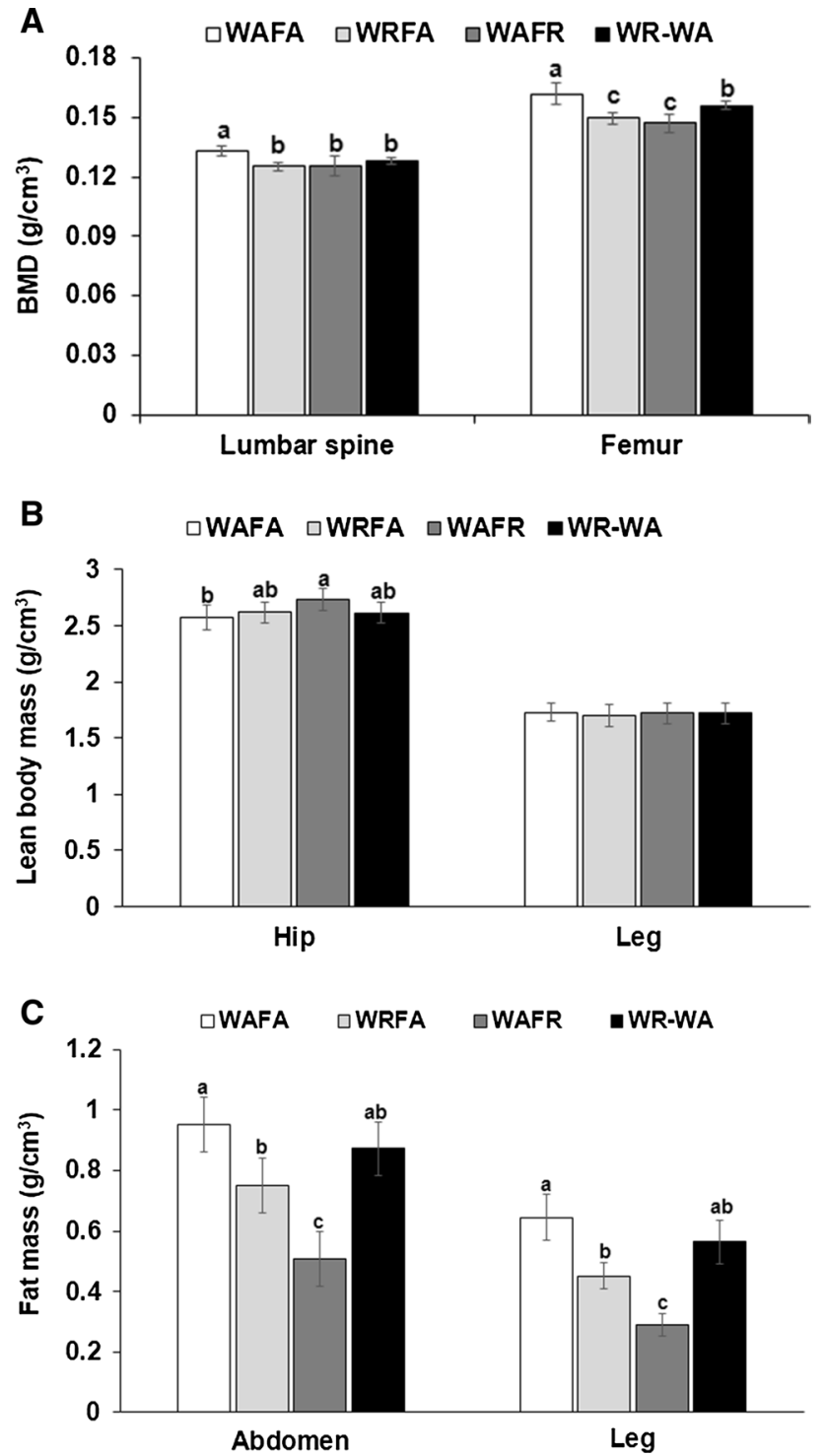

Fig. 2 Bone mineral density (BMD) and lean body mass (LBM). Female rats were assigned to the following regime for 6 weeks. Ad libitum supply of water and food (normal-control, WAFA), water supply for $1 \mathrm{~h}$ per day with ad libitum food intake (WRFA), and ad libitum water supply plus pair feeding of food to as much as WRFA (WAFR). Rats in WR-WA had water restriction for 3 weeks and ad libitum water supply with ad libitum food intake for 3 weeks. At the end of the experimental period, BMD in the lumbar spine and femur (a), LBM in the hip and leg regions (b), and fat mass in the abdomen and leg (c) were measured by DEXA. Each bar and error

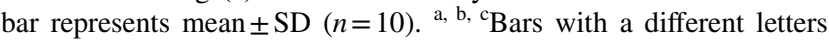
differ significantly by Tukey's test at $p<0.05$

groups $(p<0.001)$. Water restriction reduced food intake and paired food intake with sufficient water showed a bacterial distribution of decreased Firmicutes and increased Bacteroidetes compared to sufficient water and food intake (Fig. 5b). At the order level, Clostridiales was much higher in WAFA and WR-WA than in WRFA and WAFR $(p<0.05)$, and the contents of Bacteriodales was opposite of those of Clostridiales (Fig. 5c). Unlike the contents of Clostridiales and Bacteriodales, the contents of Desulfovibrionales were higher in WRFA than WAFR. WAFR, but not WRFA, increased Lactobacillales.

\section{Discussion}

The importance of water intake for good health is well accepted, but there is not a lot of supporting scientific evidence. In this study, we hypothesized that water restriction would result in metabolic disturbances that might be linked to changes in the microbiome. This was based on a small preliminary observation of such effects in rats. However, we also observed that water-restricted rats consumed less food, so we were uncertain if the effects were due entirely to water restriction or if the decreased food consumption contributed to the effects. Therefore, we included a group of mice (WAFR) that were pair-fed with the water-restricted rats (WRFA). The results showed that there were effects clearly caused by water restriction alone and there were other effects, including changes to the microbiome, which were only the result of food restriction.

In the present study, both WAFR and WRFA had less food intake than WAFA and they improved energy and lipid metabolism in comparison to the WAFA. Rieg et al. [31] also demonstrate that water restriction lowers body weight that is similar to exercise-induced weight loss. However, water restriction caused kidney damage to the glomerulus and renal tubules with increased lipid peroxide and proinflammatory cytokine contents in the kidney. Water restriction decreased expression of anti-oxidant enzymes, but sufficient water and restricted food increased their expression, thereby decreasing lipid peroxides and cytokines. Chronic dehydration induced by periodic drinking hastens the progression of chronic kidney disease and hypertension, and the damage is associated with activating renal inflammatory processes [13]. Both WRFA and WAFR decreased energy expenditure but energy substrate utilization was different: WRFA and WAFR primarily used carbohydrate and fat as energy sources, respectively. Both WRFA and WAFR lowered fat mass, but WAFR reduced the fat mass more than WRFA. Compared to WAFA, WRFA and WAFR both exhibited increased blood glucose concentrations due to lower serum insulin levels after the glucose load, but they did not exhibit glucose intolerance. However, WRFA had worsened lipid profiles in the circulation compared to the other groups. WRFA and WAFR increased Bacteroidetes and decreased Firmicutes compared WAFA. Thus, WRFA damaged the glomerulus and renal tubules although WRFA reduced food intake and modulated energy, glucose, and lipid metabolism compared to groups with sufficient water supply, WR-WA 
Table 3 Glucose and lipid metabolism

\begin{tabular}{lcccc}
\hline & WAFA & WRFA & WAFR & WR-WA \\
\hline Serum glucose (mg/dl) & $96.3 \pm 10.4^{\mathrm{a}}$ & $88.6 \pm 8.1^{\mathrm{b}}$ & $93.4 \pm 8.4^{\mathrm{ab}}$ & $97.6 \pm 8.5^{\mathrm{a}}$ \\
Serum insulin (ng/ml) & $1.54 \pm 0.21$ & $1.46 \pm 0.26$ & $1.37 \pm 0.22$ & $1.41 \pm 0.28$ \\
HOMA-IR & $5.9 \pm 0.7^{\mathrm{a}}$ & $5.2 \pm 0.7^{\mathrm{ab}}$ & $5.0 \pm 0.6^{\mathrm{b}}$ & $5.5 \pm 0.7^{\mathrm{ab}}$ \\
Serum total cholesterol (mg/dl) & $105 \pm 9.8^{\mathrm{b}}$ & $122 \pm 13^{\mathrm{a}}$ & $113 \pm 12^{\mathrm{ab}}$ & $109 \pm 12^{\mathrm{b}}$ \\
Serum LDL (mg/dl) & $62.9 \pm 6.2^{\mathrm{b}}$ & $80.3 \pm 8.3^{\mathrm{a}}$ & $67.6 \pm 8.8^{\mathrm{b}}$ & $67.5 \pm 6.9^{\mathrm{b}}$ \\
Serum HDL (mg/dl) & $28.6 \pm 2.6$ & $27.4 \pm 3.4$ & $30.9 \pm 3.9$ & $28.2 \pm 2.8$ \\
Serum TG (mg/dl) & $67.7 \pm 6.7$ & $71.6 \pm 6.4$ & $72.7 \pm 8.2$ & $67.5 \pm 7.9$ \\
Serum AST activity (U/l) & $129 \pm 14^{\mathrm{ab}}$ & $141 \pm 16^{\mathrm{a}}$ & $115 \pm 14^{\mathrm{b}}$ & $131 \pm 15^{\mathrm{ab}}$ \\
Serum ALT levels (U/l) & $22.1 \pm 4.1^{\mathrm{ab}}$ & $25.2 \pm 2.8^{\mathrm{a}}$ & $19.6 \pm 3.2^{\mathrm{b}}$ & $22.7 \pm 3.6^{\mathrm{ab}}$ \\
Liver TG ( $\mu \mathrm{g} / \mathrm{g}$ tissues) & $485 \pm 38^{\mathrm{b}}$ & $521 \pm 33^{\mathrm{a}}$ & $470 \pm 37^{\mathrm{b}}$ & $501 \pm 39^{\mathrm{ab}}$ \\
Liver glycogen $(\mu \mathrm{g} / \mathrm{g}$ tissue) & $165 \pm 11^{\mathrm{b}}$ & $172 \pm 14^{\mathrm{b}}$ & $186 \pm 6.4^{\mathrm{a}}$ & $164 \pm 16^{\mathrm{b}}$ \\
\hline
\end{tabular}

Female rats had the following regime for 6-week ad libitum supply of water and food (normal-control), water supply for $1 \mathrm{~h}$ per day with ad libitum food intake (WRFA), and ad libitum water supply plus pair feeding of food as much as WRFA (WAFR). Rats in WR-WA had water restriction for 3 weeks and ad libitum water supply with ad libitum food intake for 3 weeks. Values represent mean $\pm \operatorname{SD}(n=10)$

a, b, c Different letters besides mean \pm SD indicate significant differences among the groups at $p<0.05$ also still exhibited glomerular damage but to a somewhat lesser degree than WRFA, indicating that the kidneys were starting to heal. The gut microbiome was influenced by food intake amount much more than by water intake.

The kidney regulates extracellular fluid volume by regulating the reabsorption of water and sodium in the kidney while modulating anti-diuretic hormones. Water restriction increases serum osmolality, which places a heavy burden on the kidney. However, a few studies have described longterm health problems, like irreversible kidney damage, from repeated weight loss by water restriction [5]. However, lower-than-average fluid intake is not reported to be a cause of chronic kidney disease or acceleration of the progression of existing kidney disease. Nevertheless, in the increasing incidence of obesity and diabetes, water restriction may exacerbate kidney diseases such as kidney stones, urinary tract infection, and polycystic kidney diseases [5]. The present study showed that 6-week water restriction, consuming one-third of the normal water intake, increased oxidative stress and inflammation and induced shrinking of the glomerulus and enlargement of the renal tubules. In addition, WRFA and WR-WA to a less extent exhibited increased apoptosis of glomerular cells in the kidney section. Although the $\mathrm{Cu} / \mathrm{Zn}$ SOD and GSH-Px expressions were elevated in WRFA, MDA levels in the renal medulla were still much higher than the other groups. This indicated that WRFA greatly increased the number of reactive oxygen species, which induced the apoptosis of glomerular cells that caused renal damage. However, Zou et al. demonstrated that water restriction increases $\mathrm{Mn}-\mathrm{SOD}$ protein and activity, but not $\mathrm{Cu} / \mathrm{Zn} \mathrm{SOD}$, in the inner medulla where $\mathrm{NaCl}$ and urea are concentrated and reactive oxygen species are increased [26]. The severity and duration of water restriction may influence the damage of kidney and the decrease of food intake. The 3-week water restriction and 3-week sufficient water supply allowed the rats to recover from kidney damage in the present study. Thus, long-term water restriction may induce permanent kidney damage; however, the short-term water restriction in this study resulted in reversible kidney damage.

Water restriction influences energy, glucose, and lipid metabolism. Water restriction decreased food intake in female rats and weight loss as much as food restriction with water sufficiency in the present study. Water restriction exhibits a biphasic pattern of food intake. Food intake increases with short-term water restriction and decreases with long-term water restriction. This is influenced by hypothalamic signaling involved in food intake. Short-term water restriction upregulates mRNA expression of proopiomelanocortin, Agouti-related peptide, melanin-concentrating hormone, and orexin A in the hypothalamus in rats [32]. Plasma leptin levels also decrease. However, long-term water restriction increases plasma leptin levels in the Spinifex hopping mouse, and the hypothalamic leptin receptor mRNA expression was observed to be significantly increased [33]. As a result, long-term water restriction caused hypophagia, which decreased body weight by $20 \%$ due to loss of white adipose tissues. Thus, hormonal changes involved in food intake may contribute to fluid balance in the body during water restriction.

The present study demonstrated that WRFA increased total and LDL cholesterol levels compared to the WAFA, but did not modulate HDL cholesterol and triglyceride levels. However, WAFR increased HDL cholesterol levels compared to the other groups. Only a few studies have been conducted to determine the relationship between long-term water restriction and lipid metabolism. WRFA and WAFR reduced resting energy expenditure with lower energy intake than WAFA in the present study. Additionally, WAFR did 
Fig. 3 Serum glucose levels and areas under the curve of glucose and insulin during the oral glucose tolerance test (OGTT). Female rats were assigned to the following regime for 6 weeks. Ad libitum supply of water and food (normal-control, WAFA), water supply for $1 \mathrm{~h}$ per day with ad libitum food intake (WRFA), and ad libitum water supply plus pair feeding of food to as much as WRFA (WAFR). Rats in WR-WA had water restriction for 3 weeks and ad libitum water supply with ad libitum food intake for 3 weeks. The changes in the serum glucose levels (a) and the averages of the areas under the curve (AUC) of glucose (b) were calculated for the first part (0-40 min) and the second part (40-120 min) of the OGTT. Serum insulin levels (c) were measured during the OGTT. Each dot and bar represents the mean \pm SD $(n=10)$. *Significantly different among all groups by one-way ANOVA at $p<0.05$. ${ }^{\mathrm{a}, \mathrm{b}, \mathrm{c}}$ Each dot and bar with a different alphabet differs significantly by Tukey's test at $p<0.05$
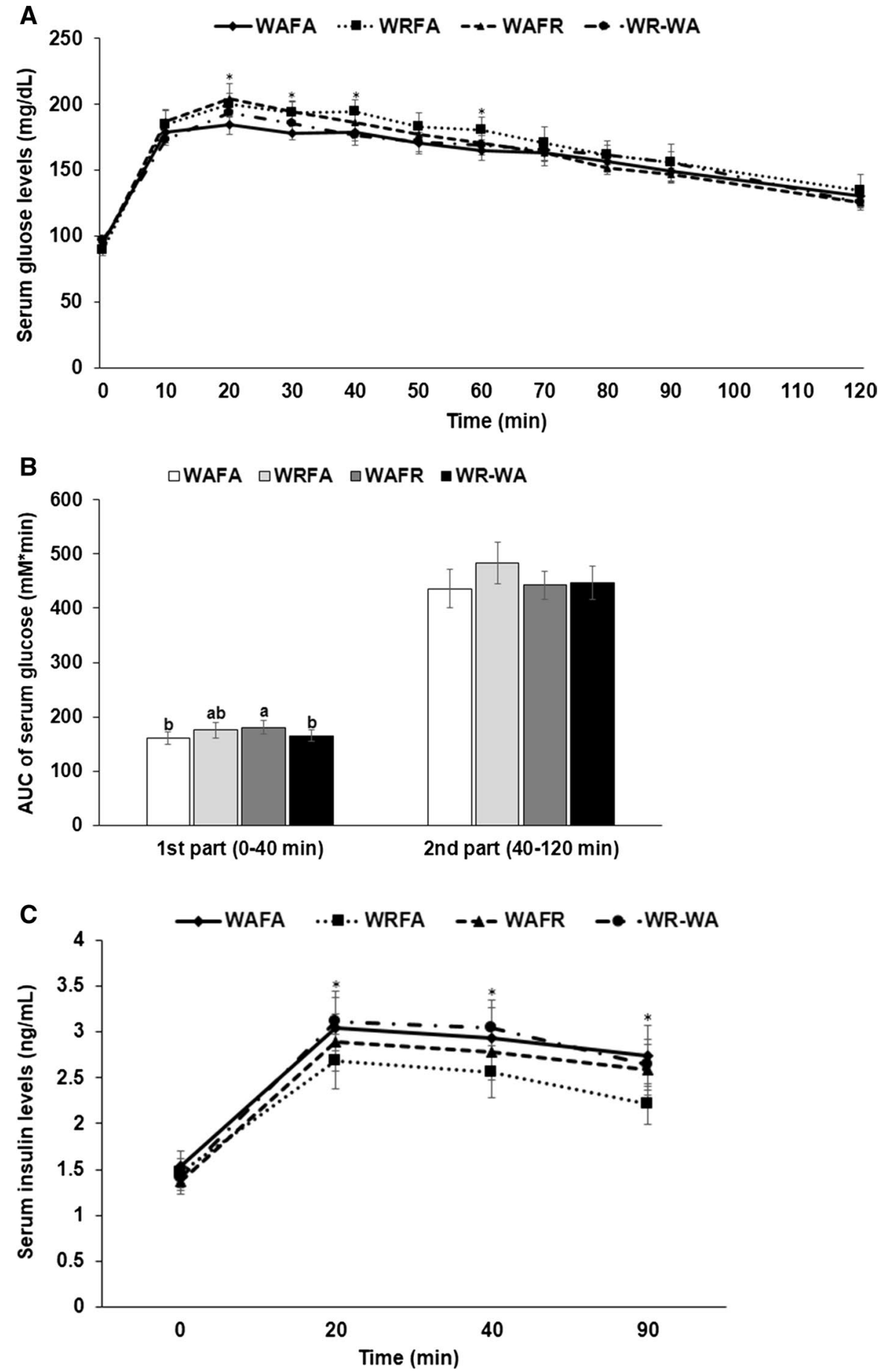

not change serum glucose, triglyceride, or total cholesterol concentrations compared to WAFA, but WAFR increased serum HDL cholesterol concentrations. Davis et al. [34] also demonstrated that caloric restriction reduces resting energy expenditure and serum insulin levels compared to the control group, but there was no difference in serum glucose and triglyceride concentrations in male rats. Serum total cholesterol concentrations were not significantly different with caloric restriction [35]. Dehydration by fasting is reported to increase serum total and LDL cholesterol levels [36]. Longterm dehydration by water restriction in WRFA may alter lipid metabolism. Thus, calorie restriction alone does not modulate lipid profiles in high-fat-diet-induced obesity.

Calorie restriction improves glucose metabolism in obesity by improving insulin sensitivity. Calorie restriction reduces serum glucose after peak glucose concentrations 

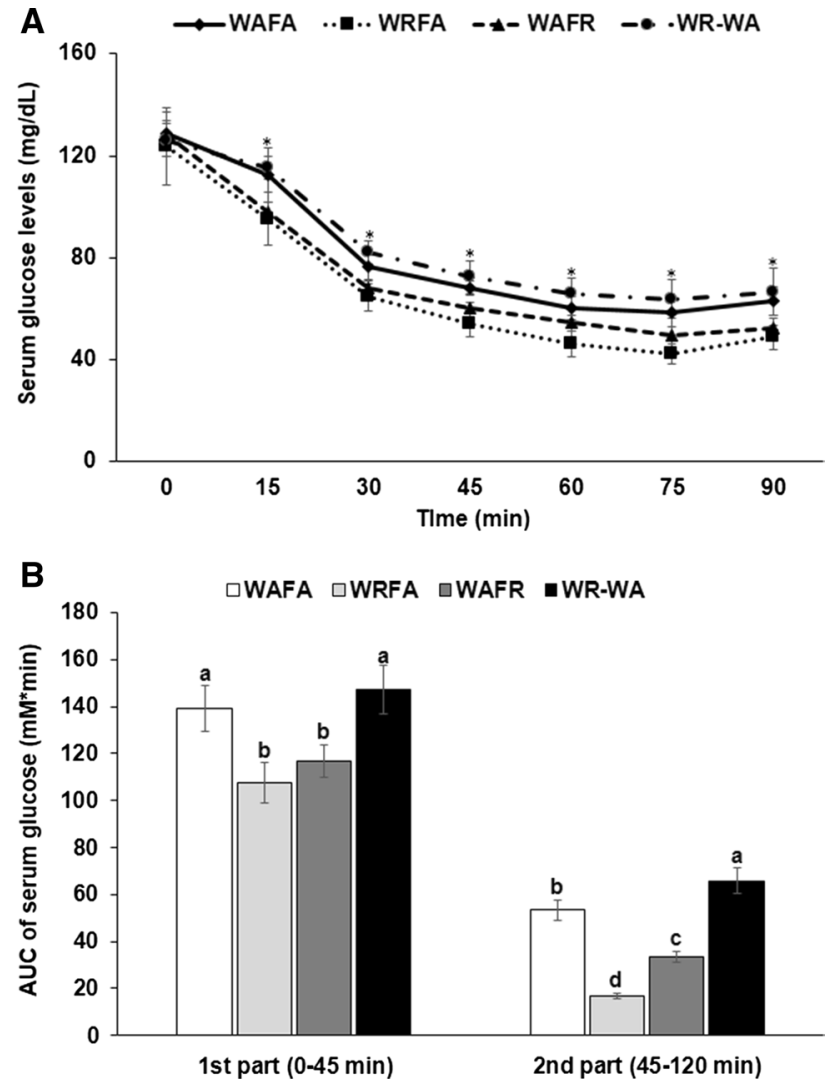

Fig. 4 Changes in the serum glucose levels during an intraperitoneal insulin tolerance test (IPITT). Female rats were assigned to the following regime for 6 weeks. Ad libitum supply of water and food (normal-control, WAFA), water supply for $1 \mathrm{~h}$ per day with ad libitum food intake (WRFA), and ad libitum water supply plus pair feeding of food to as much as WRFA (WAFR). Rats in WR-WA had water restriction for 3 weeks and then ad libitum water supply with ad libitum food intake for 3 weeks. An IPITT was conducted by intraperitoneally injecting insulin (1 U/kg body weight) after a $6 \mathrm{~h}$ fast and serum glucose levels were measured every $15 \mathrm{~min}$. The averages of the areas under the curve (AUC) of glucose (B) were calculated for the first part (0-40 $\mathrm{min})$ and the second part (40-120 $\mathrm{min})$ of the IPITT. Each bar and error bar represents mean \pm SD $(n=10)$. *Significantly different among all groups by one-way ANOVA at $p<0.05$ $(n=10)$. a, b, ${ }^{\mathrm{c}}$ Bars with a different alphabet differ significantly by Tukey's test at $p<0.05$

with lower serum insulin levels during OGTT [37], which is associated with restoring glucose-stimulated insulin secretion from islets of calorie-restricted rats. In type 2 diabetic patients, very low-calorie diets also improve $\beta$-cell function, thereby improving glycemic control [38]. The present study showed that in WAFR, serum glucose levels from the peak quickly decreased with lower serum insulin levels during OGTT. HOMA-IR was also lowered in WRFA and WAFR. The significant reduction of serum insulin levels during OGTT was observed only in WRFA and WAFR compared to the other groups. Serum insulin levels during OGTT were much lower in WRFA than WAFR. Interestingly, serum glucose levels during IPITT quickly decreased in WRFA and WAFR compared to the WAFA group, and the decrease was greater in WRFA than WAFR. This might be associated with increased utilization of glucose as a fuel source in WRFA in the present study. These results might also be associated with higher carbohydrate oxidation in WRFA than WAFR. However, WAFR utilized fat oxidation more than WRFA to reduce fat mass. Thus, water restriction promoted glucose metabolism and impaired lipid metabolism, which led to dyslipidemia.

Scientific evidence linking the gut microbiome and body weight is accumulating. Imbalances in the gut microbiota, the bacteria that inhabit the intestines, are central to the pathogenesis of obesity. Calorie restriction increases the microbiota richness and diversity that is correlated with nutrient deficiency rather than weight loss [10]. Calorie restrictive diets generally reduce the butyrate-producing bacteria such as Firmicutes, Lactobacillus, and Bifidobacterium species [39]. The changes in gut microbiota resulting from calorie restriction are similar to those induced by bariatric surgery in experimental animals and humans [39, 40]. Calorie restriction and bariatric surgery modulate bile acid metabolism to increase circulating bile acid concentrations and reduced the secondary bile acid production. The present study also showed that WAFR and WRFA reduced Firmicutes and increased Bacteroidetes regardless of water intake. However, in the present study, WAFR, not WRFA, increased Lactobacillales, which was comparable to the results of Pan et al. [41]. However, no study has investigated how the gut microbiome is modulated by water restriction. These results suggest that food restriction influenced the changes in the gut microbiome at the phylum level regardless of water restriction, but water restriction may influence gut microbiome at the order and genus levels.

\section{Conclusions}

Chronic insufficient water intake with water restriction induced renal damage by increasing lipid peroxides and proinflammatory cytokines, but appeared to partially improve when water access was restored. It also decreased energy expenditure and exacerbated dyslipidemia under the same food intake. However, the gut microbiome was modulated by food restriction more than water restriction, and the microbiome exhibited only minor changes due to water restriction. Thus, water sufficiency may be important for maintaining normal metabolism during weight loss. 


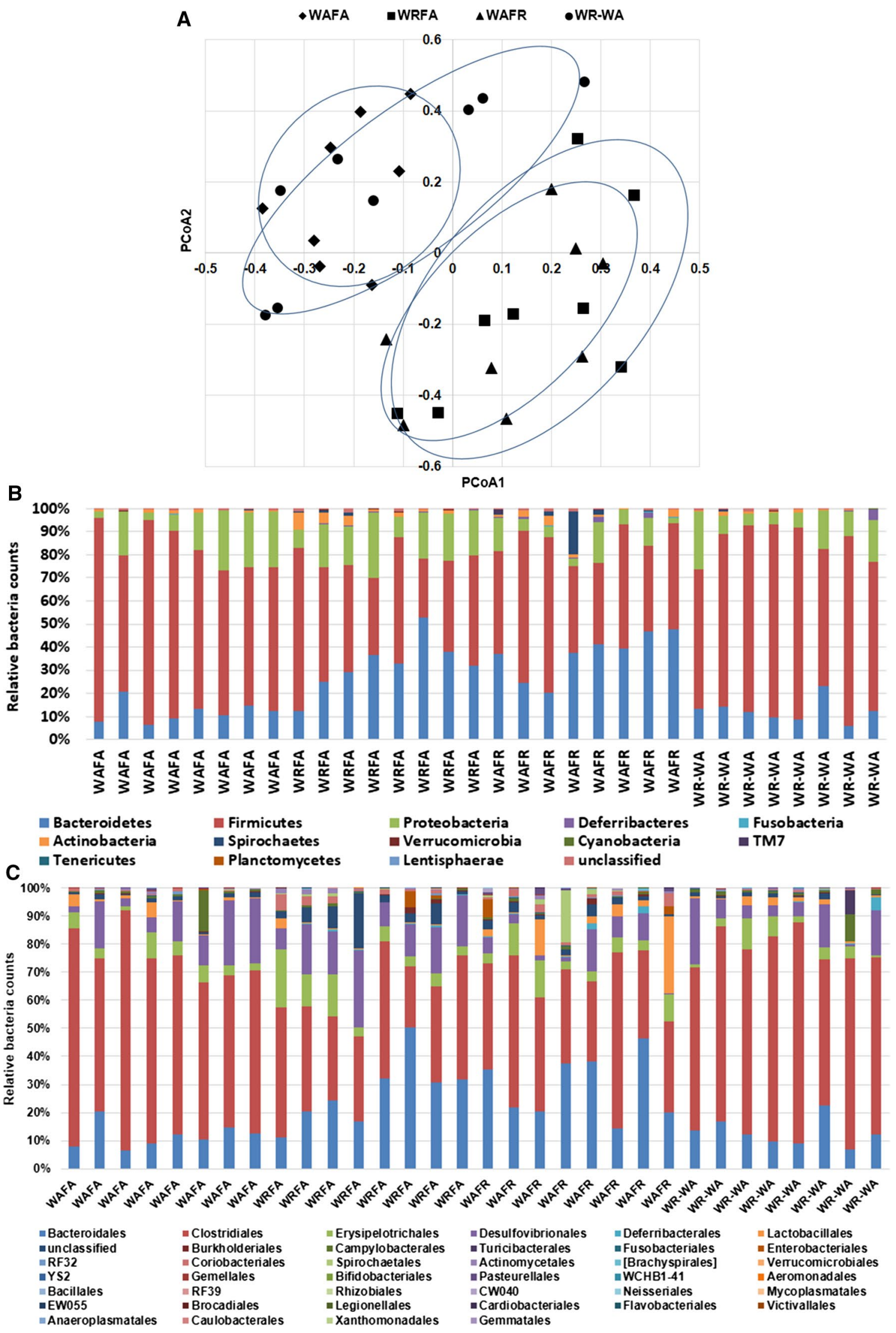


4Fig. 5 Profiles of gut microbiomes. Female rats were assigned to the following regime for 6 weeks. Ad libitum supply of water and food (normal-control, WAFA), water supply for $1 \mathrm{~h}$ per day with ad libitum food intake (WRFA), and ad libitum water supply plus pair feeding of food to as much as WRFA (WAFR). Rats in WR-WA had water restriction for 3 weeks and ad libitum water supply with ad libitum food intake for 3 weeks. Feces were collected and the bacterial DNA was analyzed $(n=8)$. The fecal bacterial community was shown in the principal coordinate analysis (PCoA) (a). The proportion of taxonomic assignments (phylum) (b) and [order] (c) for gut microbiomes was analyzed

Author contributions JWD and SP designed the research. XW and TZ performed animal experiments. SP performed statistical analyses. JWD and SP drafted the article. All authors discussed the results and implications and commented on the manuscript at all stages. All authors contributed to the writing and editing of the article.

Funding This research was supported by the Academic Research Fund of Hoseo University in 2017 (2017-0103).

\section{Compliance with ethical standards}

Conflict of interest The authors declare that there are no conflicts of interest.

Ethical approval All experimental procedures were conducted according to the Guide for the Care, and Use of Laboratory Animals from the National Institutes of Health (NIH) and were approved by the Institutional Animal Care and Use Committee of Hoseo University (HUACUC-17-47).

\section{References}

1. Westerterp KR, Plasqui G, Goris AH (2005) Water loss as a function of energy intake, physical activity and season. Br J Nutr 93:199-203

2. Jequier E, Constant F (2010) Water as an essential nutrient: the physiological basis of hydration. Eur J Clin Nutr 64:115-123

3. Armstrong LE, Johnson EC, McKenzie AL, Munoz CX (2016) An empirical method to determine inadequacy of dietary water. Nutrition 32:79-82

4. Nakamura K, Velho G, Bouby N (2017) Vasopressin and metabolic disorders: translation from experimental models to clinical use. J Intern Med 282:298-309

5. Feehally J, Khosravi M (2015) Effects of acute and chronic hypohydration on kidney health and function. Nutr Rev 73(Suppl 2):110-119

6. MacManes MD (2017) Severe acute dehydration in a desert rodent elicits a transcriptional response that effectively prevents kidney injury. Am J Physiol Renal Physiol 313:F262-F272

7. Scrogin KE, Grygielko ET, Brooks VL (1999) Osmolality: a physiological long-term regulator of lumbar sympathetic nerve activity and arterial pressure. Am J Physiol 276:R1579-R1586

8. Melander O (2016) Vasopressin, from regulator to disease predictor for diabetes and cardiometabolic risk. Ann Nutr Metab 68(Suppl 2):24-28
9. Woolsey CA, Coopersmith CM (2006) Vasoactive drugs and the gut: is there anything new? Curr Opin Crit Care 12:155-159

10. Heinsen FA, Fangmann D, Muller N, Schulte DM, Ruhlemann MC, Turk K et al (2016) Beneficial effects of a dietary weight loss intervention on human gut microbiome diversity and metabolism are not sustained during weight maintenance. Obes Facts 9:379-391

11. Kaska L, Sledzinski T, Chomiczewska A, Dettlaff-Pokora A, Swierczynski J (2016) Improved glucose metabolism following bariatric surgery is associated with increased circulating bile acid concentrations and remodeling of the gut microbiome. World $\mathbf{J}$ Gastroenterol 22:8698-8719

12. Leenen FH, de Jong W (1981) Hypotensive effect of water restriction in the two-kidney one-clip hypertensive rat. Am J Physiol 241:F525-F531

13. Hilliard LM, Colafella KMM, Bulmer LL, Puelles VG, Singh RR, Ow CPC et al (2016) Chronic recurrent dehydration associated with periodic water intake exacerbates hypertension and promotes renal damage in male spontaneously hypertensive rats. Sci Rep 6:33855

14. Park F, Koike G, Cowley AW Jr (1998) Regional time-dependent changes in vasopressin $\mathrm{V} 2$ receptor expression in the rat kidney during water restriction. Am J Physiol 274:F906-F913

15. Chang T, Ravi N, Plegue MA, Sonneville KR, Davis MM (2016) Inadequate hydration, BMI, and obesity among US adults: NHANES 2009-2012. Ann Fam Med 14:320-324

16. Thornton SN (2016) Increased hydration can be associated with weight loss. Front Nutr 3:18

17. Milla-Tobarra M, Garcia-Hermoso A, Lahoz-Garcia N, NotarioPacheco B, Lucas-de la Cruz L, Pozuelo-Carrascosa DP et al (2016) The association between water intake, body composition and cardiometabolic factors among children-the Cuenca study. Nutr Hosp 33:312

18. Reeves PG, Nielsen FH, Fahey GC Jr (1993) AIN-93 purified diets for laboratory rodents: final report of the American Institute of Nutrition ad hoc writing committee on the reformulation of the AIN-76A rodent diet. J Nutr 123:1939-1951

19. Park S, Kim DS, Kang ES, Kim DB, Kang S (2018) Low dose brain estrogen prevents menopausal syndrome while maintaining the diversity of the gut microbiomes in estrogen-deficient rats. Am J Physiol Endocrinol Metab. https://doi.org/10.1152/ajpen do.00005.2018

20. Niwa H, Ogawa Y, Kido Y, Abe Y, Kobayashi M, Mori T et al (1989) The rate of lipid oxidation in septic rat models. Jpn J Surg 19:439-445

21. Even PC, Nadkarni NA (2012) Indirect calorimetry in laboratory mice and rats: principles, practical considerations, interpretation and perspectives. Am J Physiol Regul Integr Comp Physiol 303:R459-R476

22. Yang HJ, Kwon DY, Kim MJ, Kim DS, Kang S, Shin BK et al (2014) Red peppers with different pungencies and bioactive compounds differentially modulate energy and glucose metabolism in ovariectomized rats fed high fat diets. J Funct Foods 7:246-256

23. Park S, da Kim S, Kang S (2011) Gastrodia elata Blume water extracts improve insulin resistance by decreasing body fat in dietinduced obese rats: vanillin and 4-hydroxybenzaldehyde are the bioactive candidates. Eur J Nutr 50:107-118

24. Park S, Kim DS, Kang S (2016) Vitamin D deficiency impairs glucose-stimulated insulin secretion and increases insulin resistance by reducing PPAR-gamma expression in nonobese type 2 diabetic rats. J Nutr Biochem 27:257-265

25. Yang HJ, Kim MJ, Kwon DY, Moon BR, Kim AR, Kang S et al (2016) The combination of Artemisia princeps Pamp, Leonurus japonicas Houtt, and Gardenia jasminoides Ellis fruit attenuates the exacerbation of energy, lipid, and glucose by increasing 
hepatic PGC-1alpha expression in estrogen-deficient rats. BMC Complement Altern Med 16:137

26. Zhou X, Burg MB, Ferraris JD (2012) Water restriction increases renal inner medullary manganese superoxide dismutase (MnSOD). Am J Physiol Renal Physiol 303:F674-F680

27. Park S, Kim DS, Kang S, Shin BK (2015) Synergistic topical application of salt-processed Phellodendron amurense and Sanguisorba officinalis Linne alleviates atopic dermatitis symptoms by reducing levels of immunoglobulin $\mathrm{E}$ and pro-inflammatory cytokines in NC/Nga mice. Mol Med Rep 12:7657-7664

28. Livak KJ, Schmittgen TD (2001) Analysis of relative gene expression data using real-time quantitative PCR and the 2(-Delta Delta $\mathrm{C}(\mathrm{T})$ ) method. Methods 25:402-408

29. Park S, Hong SM, Lee JE (1985) Sung SR (2007) Exercise improves glucose homeostasis that has been impaired by a highfat diet by potentiating pancreatic beta-cell function and mass through IRS2 in diabetic rats. J Appl Physiol 103:1764-1771

30. Goodrich JK, Di Rienzi SC, Poole AC, Koren O, Walters WA, Caporaso JG et al (2014) Conducting a microbiome study. Cell 158:250-262

31. Rieg TS, Doerries LE, O'Shea JG, Aravich PF (1993) Water deprivation produces an exercise-induced weight loss phenomenon in the rat. Physiol Behav 53:607-610

32. Ruginsk SG, Vechiato FM, Uchoa ET, Elias LL, Antunes-Rodrigues J (2015) Type 1 cannabinoid receptor modulates water deprivation-induced homeostatic responses. Am J Physiol Regul Integr Comp Physiol 309:R1358-R1368

33. Donald JA, Hamid NK, McLeod JL (2017) The role of leptin and ghrelin in appetite regulation in the Australian Spinifex hopping mouse, Notomys alexis, during long-term water deprivation. Gen Comp Endocrinol 244:201-208

34. Davis RAH, Halbrooks JE, Watkins EE, Fisher G, Hunter GR, Nagy TR et al (2017) High-intensity interval training and calorie restriction promote remodeling of glucose and lipid metabolism in diet-induced obesity. Am J Physiol Endocrinol Metab 313:E243-E256

35. Pires RC, Souza EE, Vanzela EC, Ribeiro RA, Silva-Santos JC, Carneiro EM et al (2014) Short-term calorie restriction improves glucose homeostasis in old rats: involvement of AMPK. Appl Physiol Nutr Metab 39:895-901

36. Campbell NR, Wickert W, Magner P, Shumak SL (1994) Dehydration during fasting increases serum lipids and lipoproteins. Clin Invest Med 17:570-576

37. Amaral ME, Ribeiro RA, Vanzela EC, Barbosa-Sampaio HC (2016) Reduced AMPKalpha2 protein expression restores glucose-induced insulin secretion in islets from calorie-restricted rats. Int J Exp Pathol 97:50-55

38. Malandrucco I, Pasqualetti P, Giordani I, Manfellotto D, De Marco F, Alegiani F et al (2012) Very-low-calorie diet: a quick therapeutic tool to improve beta cell function in morbidly obese patients with type 2 diabetes. Am J Clin Nutr 95:609-613

39. Seganfredo FB, Blume CA, Moehlecke M, Giongo A, Casagrande DS, Spolidoro JVN et al (2017) Weight-loss interventions and gut microbiota changes in overweight and obese patients: a systematic review. Obes Rev 18:832-851

40. Ruiz A, Cerdo T, Jauregui R, Pieper DH, Marcos A, Clemente A et al (2017) One-year calorie restriction impacts gut microbial composition but not its metabolic performance in obese adolescents. Environ Microbiol 19:1536-1551

41. Pan F, Zhang L, Li M, Hu Y, Zeng B, Yuan H et al (2018) Predominant gut Lactobacillus murinus strain mediates anti-inflammation effects in calorie-restricted mice. Microbiome 6:54

Publisher's Note Springer Nature remains neutral with regard to jurisdictional claims in published maps and institutional affiliations. 